\title{
A formação de professores nos cursos de Ciências Naturais (LCN) no Brasil no século XXI: perspectiva de alunos e professores
}

Teacher training in Natural Sciences (LCN) Courses in Brazil in the 21 ${ }^{\text {st }}$ Century: Students and teachers' Perspective

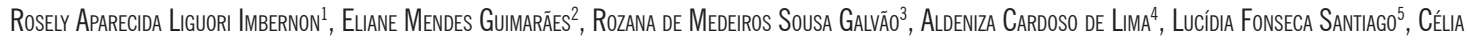
Maria Lira Jannuzzi ${ }^{6}$, Tiago Calixto ${ }^{7}$

1 - Professor Associado 2, Escola de Artes, Ciênclas e Humanidades (EACH), Universdade de São Paulo (USP). Docente no Programa de Pós Graduaģão em ENIINO E HISTÓRIA E ClênCIAS dA TeRRA (PPG-EHCT), IG, UNICAMP.

2 - Professor Adjunto, Faculdade UnB Planalina (FuP), Universidade de Brasilla (UnB),

3 - Diretora, Instituto de Ciencias Biológicas, Universidade Federal do Amazonas (UFAM).

4 - Professor Adunto, Instituto de Clencias Biologicas, Depto.de Biológia, Universidade Federal do Amazonas (UFAM).

5 - 5Professor Associado, Programa de Pós-Graduaç̄o Clênclas e Melo Ambiente, Universidade Federal do Pará (UFPA).

6 - Professor Adunto, Unversidade Federal Fluminense (UFF).

7 - Pós-Graduando no Programa de Pós Graduação em Ensino e História e Clênclas da Terra (PPG-ehCT), IG, Unicamp.

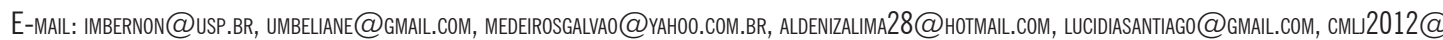
GMALl.COM, TIAGO_CALIXT@@OUTLOOK.COM

Abstract: In August 2008, the University of Brasilia/Planaltina Campus organized the 1st Brazilian Seminar for Integration of Natural Sciences Teacher Preparation Programs (LCN), which took place December 8 to 10, 2008, in Planaltina (DF), Brazil. Coordinators and/or representatives of courses from the following states attended: São Paulo (University of São Paulo), Pará (Federal University of Pará and State University of Pará), Amazonas (University of Amazonas), Bahia (State University of Bahia), Acre (Federal University of Acre), Mato Grosso (Federal University of Mato Grosso), Rio de Janeiro (Fluminense Federal University ), and Minas Gerais (Federal University of Minas Gerais). The objective of the Seminar was to bring together the universities involved in teacher preparation in the Natural Sciences, to build a knowledge network. After that meeting, several others were organized, involving course coordinators, teachers and students of LCN courses, which established a debate regarding training of Natural Sciences teachers in the country. Themes involving the national curricular guidelines and the field of work of alumni were some of the topics discussed.

Resumo: Em 2008, na Universidade de Brasília, Campus de Planaltina (UnB-Planaltina), no $1^{0}$ Seminário Brasileiro de Integração das Licenciaturas em Ciências Naturais (LCN), estiveram presentes coordenadores e/ou representantes de cursos de Licenciatura em Ciências Naturais de SP (Universidade de São Paulo), PA (Universidade Estadual do Pará e Universidade Federal do Pará), do Amazonas (Universidade Federal do Amazonas), BA (Universidade Estadual da Bahia), AC (Universidade Federal do Acre), MT (Universidade Federal do Mato Grosso), RJ (Universidade Federal Fluminense) e MG (Universidade Federal de Minas Gerais) O Seminário objetivou aproximar as universidades envolvidas na formação de professores de Ciências Naturais, de modo a formar uma rede de conhecimento. A reunião foi sucedida por outras, que promoveram debates e trocas de experiência sobre formação de professores de Ciências Naturais, envolvendo coordenadores de cursos, professores e alunos de cursos LCN. Os temas discutidos envolvem diretrizes curriculares nacionais e campos de atuação dos egressos.
Citation/Citação: Imbernon, R. A. L., Guimarães, E. M., Galvão, R. M. S., Lima, A. C.,Santiago, L. F., Jannuzzi, C. M. L., \& Calixto, T. (2020). A formação de professores nos cursos de Ciências Naturais (LCN) no Brasil no século XXI: perspectiva de alunos e professores. Terræ Didatica, 16, 1-9, e020030. doi: 10.20396/ td.v16i0.8659017

Keywords: Curricula. Interdisciplinarity. Geosciences. Teaching.

Palavras-chave: Currículos. Interdisciplinaridade. Geociências. Ensino.

Manuscript/Manuscrito:

Received/Recebido: 08/04/2020

Revised/Corrigido: 26/05/2020

Accepted/Aceito: 22/06/2020

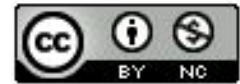

\section{Introdução}

Em uma sociedade cada vez mais orientada pela Ciência e pela Tecnologia, a formação docente apresenta alta complexidade, principalmente para aqueles que se tornarão professores de Ciências Naturais. Além dos saberes relacionados ao ensino de Ciências, há que se considerar que o professor deverá propiciar ao seu aluno aprender a pensar e agir no contexto do pensamento científico, entender que a pesquisa cientifica é propriedade da sociedade e, neste contexto, possibilitar o desenvolvimento das competências comunicativas e o pensamento crítico para a formação de um cidadão capaz de transformar a sociedade em que vive.

\begin{tabular}{|c|c|c|c|c|c|}
\hline (c) Terrae Didat. & Campinas, SP & v.16 & $1-9$ & $\mathrm{e} 020030$ & 2020 \\
\hline
\end{tabular}


Neste contexto, a formação de professores de Ciências Naturais deve dar conta das exigências introduzidas pela demanda de novos conteúdos curriculares, mais adequados à vida cotidiana, mais atualizados quanto às conquistas científicas e tecnológicas, mais refinados quanto às implicações culturais, mais profundos quanto aos recursos psicológicos, mais eficientes quanto às metodologias e mais inclusivos quanto à dimensão ética (Villani et al., 2002).

Souza et al. (2019) apontam que na formação continuada para professores um dos principais fatores envolve estabelecer uma abordagem que possa aumentar a autoestima docente.

"É necessário envolvê-los de forma que possam perceber que é possível se redescobrir como educador e reconhecer que o conhecimento e o aprendizado constituem uma via de mão dupla... formações docentes costumam ter como foco principal demandas pedagógicas, porém não fazem relações com as disciplinas ensinadas na escola. Torna-se necessário envolver os professores em atividades de planejamento coletivo, de forma que os discursos possam estimular o aprendizado de práticas pedagógicas atreladas ao objeto de estudo das disciplinas quelecionam" (Souza et al., 2019).

A história do ensino de ciências no ensino fundamental no país é muito recente; a formação de professores envolve estabelecer a formação de alunos reflexivos, críticos, capazes de desenvolver habilidades efetivas e um pensamento crítico em relação às intensas transformações observadas entre o final do século XX e o início do século XXI. Saviani (2006) afirma que somente a educação poderá proporcionar um desenvolvimento integral do ser humano, tanto no plano intelectual quanto emocional.

Assim, o desempenho de alunos brasileiros no Programa Internacional de Avaliação de Alunos (PISA) tem revelado que o ensino deficiente de ciências leva o país a ocupar uma das últimas posições. Em 2018, em proficiência na área de ciências, $55 \%$ dos alunos não atingiram o nível básico (INEP, 2019).

Soares et al. (2012) indicam que a avaliação dos alunos brasileiros, em relação aos demais países, no que concerne às habilidades cognitivas, não é um fator fácil, pois a cada rodada do Pisa, há vários novos países participantes - e alguns poucos que ficam de fora devido a problemas técnicos ou discordâncias políticas. Os autores apontam, ainda, que a evolução positiva do Brasil no PISA ainda é muito incipiente para elevar a posição do país em relação aos demais.

No Brasil, o ensino de Ciência apresenta um histórico que pode ser estruturado em função da história política do país. O cenário do Ensino de Ciências no Brasil estabelece quatro períodos: de 1950 a 1960; de 1960 a 1970; de 1970 a 1980 e de 1980 a 1985 (Krasilchik, 1987), e durante a primeira década do século XXI, a implantação de cursos de Licenciatura em Ciências da Natureza (ou Ciências Naturais) no âmbito do Programa de Reestruturação e Expansão das Universidades Federais (Reuni), alterou o cenário de formação de professores para ensino de Ciências no Ensino Fundamental 2.

Nardi (2005) aponta que entre o final da década 1940 e início da década de 1950 diversos movimentos isolados facilitaram a constituição de grupos de pesquisa em ensino de ciências no Brasil, especialmente em 1946, com a criação do Instituto Brasileiro de Educação, Ciência e Cultura (IBECC), o qual se destinou a implantar diversos projetos de ensino de ciências no país. Tais projetos incluíam o apoio a pesquisas e treinamento de professores e atividades escolares como feiras, museus e clubes de ciências. Em 1952, com o apoio da Fundação Rockefeller e Ministério da Educação, foram criados os primeiros materiais destinados ao aprendizado de Química para o atual ensino médio; e em 1955 foi desenvolvido o projeto de Iniciação Científica, com o objetivo de desenvolver material didático prático e investigatório para os cursos primário e secundário objetivando o aprendizado de Física, Química e Biologia.

No que se refere aos currículos, somente no período entre 1950 e 1960 identificamos a influência do desenvolvimento tecnológico e cientifico pós II Guerra Mundial, o que implementou um movimento realizado pelo IBECC, com justificativa de que o ensino de Ciências brasileiro, à época, era precário, assumindo a tarefa de modificá-lo. Um dos principais objetivos desse movimento era “... atualizar os conteúdos então ensinados nas escolas secundárias, e tornar o ensino prático" (Krasilchik, 1980, p. 164). Em 1959 houve renovação, em diversos países, no ensino e aprendizagem de Ciências nos cursos secundários, diante de fatos científicos e tecnológicos, tais como a corrida espacial, protagonizada pela antiga União Soviética e Estados Unidos da América (EUA), que favoreceu renovação significativa nos currículos escolares de Ciências, com produção de novos materiais didáticos.

Neste cenário, somente a partir da década de 1960 encontraremos no Brasil, a partir da Lei 
4.024/61, Lei de Diretrizes e Bases da Educação (LDB), a obrigatoriedade de inserção da disciplina de ciências nos currículos da educação básica (Krasilchik, 1987). Muito embora à mesma época tenha havido muitas críticas em relação à formação de professores, encontramos uma ponderação de Pontuschka (1994) que expõe que:

(...) o professor não poderá oferecer ao aluno aquilo que ele não possui; entretanto, se ele conhecer só o conteúdo de uma disciplina, ele irá apenas discursar sobre esse conhecimento e isso não é suficiente para formar o cidadão, pois o professor deve oferecer algo mais, ensinando o aluno a construir o caminho através da utilização do método de construção do conhecimento da ciência.

De fato, a formação de professores de ciências tem sido foco de distintas pesquisas, porém, como aponta Compiani (2005):

(...) o desenvolvimento do profissionalismo do professor é mais complexo e não basta introduzir produtos acabados para aplicação pelos professores em suas escolas; agora é necessário que a introdução de estratégias e processos tenha como foco a formação dos professores, de maneira que eles elaborem seus métodos e produtos do ensino-aprendizagem de acordo com a realidade concreta de suas escolas.

Entretanto, a dificuldade está exatamente em atender tais exigências de conteúdo curricular, impróprio, muitas vezes, para a complexa formação do professor de Ciências Naturais. Oliveira \& Imbernon (2014) ao avaliarem as diretrizes curriculares dos cursos de licenciatura em Química, Física e, mais especificamente, de Ciências Biológicas, observaram que não há uma distinção clara entre o que se definem como diretrizes para os alunos formados em cursos "bacharelados", daqueles que se formarão professores, as "licenciaturas”. As autoras ressalvam uma leve exceção para os cursos de Química e identificaram, ainda, que os cursos de Licenciatura em Ciências Naturais (LCN) no Brasil não apresentam Diretrizes Curriculares (DCN) distintas, tendo como referência as diretrizes curriculares de Ciências Biológicas.

Além dos pontos levantados, existe a tríplice crise na formação de professores, não só em Ciências Naturais, mas em todas as áreas, que é explicada por Ristoff (2012):
(...) a crise de quantidade manifesta-se em todas as disciplinas da educação básica e em todas as regiões do país... não há uma única disciplina em que o número de professores com formação específica seja igual ou superior à demanda. (...) Já a crise da qualidade se identifica pelo improviso de professores, identificada nos exames de avaliação de rendimento econômico, além dos altos índices de evasão dos licenciados; as licenciaturas com cara de bacharelados; a apartheid que distancia a universidade da escola; os ambientes de aprendizagem inadequados e o fato de as instituições privadas sofrerem com a baixa qualidade. (...) O principal programa neste contexto é o Plano Nacional de Formação dos Professores de Educação Básica (Parfor)... as chances de êxito, no entanto, esbarram na crise sistêmica que envolve toda a educação brasileira (Ristoff, 2012).

De fato, ao nos remetermos à Base Nacional Comum Curricular (BNCC), devemos considerar múltiplos aspectos, uma vez que os professores atualmente na sala de aula e aqueles ainda em formação, são pessoas distintas, cujos processos de formação escolar são bastante variados. Devemos considerar ainda que também deve ser revistos os processos de formação inicial e continuada de professores. A partir da introdução da BNCC, ficou definido que:

(...) as novas diretrizes não apenas fundamentariam a concepção, formulação, implementação, avaliação e revisão dos currículos e das propostas pedagógicas das instituições escolares, como também deveriam contribuir para a coordenação nacional do devido alinhamento das políticas e ações educacionais, especialmente a política para formação inicial e continuada de professores. Assim, é imperativo inserir o tema da formação profissional para a docência no contexto de mudança que a implementação da BNCC desencadeia na Educação Básica (CNE, 2019).

Podemos perceber nesse processo histórico que o ensino de ciências no País é recente e apresenta resultados insuficientes, levando-nos a considerar que um dos problemas está no modelo de formação dos professores, que oscila entre a especificidade disciplinar e a generalidade.

A implantação de cursos de Licenciatura em Ciências da Natureza (ou Ciências Naturais, LCN), se apresenta, também, como fato recente no cenário da formação de professores de Ciências pelas instituições de ensino superior (IES) no Brasil. O 
Programa do Governo Federal de Apoio a Planos de Reestruturação e Expansão das Universidades Federais Brasileiras (Reuni), foi parte integrante de um conjunto de ações do Governo Federal no Plano de Desenvolvimento de Educação (PDE) do MEC, instituído pelo Decreto n ${ }^{\circ}$ 6.096, de 24 de abril de 2007.

Os cursos de LCN foram os que mais se difundiram com o Reuni, no entanto, não houve, à época, por parte do Ministério da Educação, ações junto ao Conselho Nacional de Educação (CNE) para formalizar diretrizes específicas para os novos cursos.

\section{Os cursos de Ciências da Natureza em debate: Seminário de Cursos de LCN}

Desde 2008, a partir de um encontro de coordenadores de cursos de Licenciatura em Ciências Naturais de diferentes regiões do país, realizado na Universidade de Brasília (UnB, campus Planaltina). Durante o evento, o ensino de Ciências foi debatido pelos participantes e pesquisadores externos convidados em nível nacional, para estabelecer um quadro exato dos problemas que outros cursos estariam vivenciando em outros estados. Percebeu-se, na oportunidade, que desconhecíamos quantos cursos existiam e de como estavam sendo articulados os projetos políticos pedagógicos ${ }^{1}$. Estiveram presentes os coordenadores e/ou representação dos cursos de São Paulo (EACH/USP), do Pará (UEPA e UFPA), do Amazonas (UFAM), da Bahia (UNEB Campus Alagoinha), do Acre (UFAC- Rio Branco e UFAC campus Cruzeiro do Sul), Mato Grosso (UFMT), Rio de Janeiro (UFF campus Santo Antônio de Pádua e campus Niterói), Minas Gerais (UFMG), Rio Grande do Sul (UFSM). O objetivo do seminário foi de aproximar as universidades envolvidas na formação de professores de Ciências Naturais, formando uma rede de conhecimento.

Naquele momento, questões como habilitações para o ensino médio e Diretrizes Curriculares foram apontados como questões que deveriam pautar um debate no nível nacional.

De fato, Reis et al. (2020) realizaram um estudo sobre os cursos de LCN no Brasil e observaram, da mesma forma como apontavam os debates de

$101^{\circ}$ Seminário Brasileiro de Integração das Licenciaturas em Ciências Naturais ocorreu no período de 08 a 10 de dezembro de 2008, na Faculdade UnB/Planaltina. Embora o debate estivesse centrado nos cursos de LCN, foram convidados coordenadores de cursos de Licenciatura em Educação do Campo e Curso Superior de Formação de Professor Indígena.
2008, que a formação de professores de Biologia, em cursos de Licenciatura em Ciências Biológicas é mais expressiva em relação àquela oferecida aos formados em LCN, dado que aponta um significativa discrepância na formação de professores de ciências para lecionar exclusivamente no ensino fundamental.

Os debates foram profícuos e permitiram que todos encontrassem temas comuns de discussão para seus cursos. As formas de avaliação do curso, perfil do futuro professor de Ciências Naturais e possibilidades de atuação do licenciando em Ciências Naturais, além do magistério, foram pontos de concordância em que pesaram de forma significativa os questionamentos dos alunos presentes. Foram formados três grupos de trabalho, convidando-se os alunos à participação, discussão dos temas e síntese dos principais pontos da discussão:

- Grupo 1 - Diretrizes para o curso de Licenciatura em Ciências Naturais - LCN

- Grupo 2 - Perfil do futuro professor de Ciências Naturais - Propostas

- Grupo 3 - Possibilidades de atuação do licenciando em ciências naturais.

Dos três grupos de trabalho somente o Grupo 1 não conseguiu definir encaminhamentos. Um dos fatores que contribuíram para esse desfecho foi o fato de que alguns cursos, à época, ainda apresentarem habilitações para atuação no ensino médio (Biologia, Química, Física, Matemática). Porém, esse grupo foi concordante em indicar a necessidade de ampliar e fomentar a discussão sobre Diretrizes Curriculares para LCN, além de apontar a necessidade de um mapeamento do número de cursos de LCN no país.

O Grupo 2 apontou os seguintes itens associados ao perfil do futuro professor de Ciências: Ser Educador; Visão Crítica, inovadora; Estímulo ao diálogo; Formação mais abrangente, qualitativa, com capacidade de dialogar c/ as diferentes disciplinas, sem ser um especialista; Olhar para/com o sujeito; Despertar a curiosidade; Capacidade de selecionar informações e transformá-las em conhecimento confiável e adequado a diferentes níveis de escolarização; Pensar na atividade pedagógica de forma investigativa (professor-pesquisador); Compromisso social; Capacidade de propiciar o debate aos estudantes em torno de questões sócio científicas; Compreender as grandes ideias estruturadoras das áreas de Química, Física, Biologia, Astronomia e Geociências; Figura 
estratégica para promoção da Educação Ambiental; Autogestão do aprendizado; Sensibilizar-se pelas questões legais acerca de seu papel como professor e pelas questões da infância, adolescência; Propiciar aos alunos o desenvolvimento de atividades investigativas; Aplicação do conhecimento no cotidiano; Capaz de discutir a natureza, ambiente, sociedade, tecnologia; Trabalhar com atividades formais, não formais e informais.

O Grupo 3 teve participação bastante ativa dos alunos e apresentou as seguintes propostas de atuação profissional: Ensino básico (ensino fundamental e ensino médio em Ciências Naturais); Educação Ambiental; Divulgação Científica; Educação não formal e informal (ONG), Museus, etc.; Ministério da Educação, Ciência e Tecnologia; Consultoria Ambiental; Ibama, Embrapa; Pesquisador de Instituições; Pesquisa em Ensino de Ciências; Pesquisa em Ciências Naturais.

Foram também realizadas as apresentações dos projetos políticos pedagógicos (PPP) por cada representante ali presente de cursos, por estado, o que permitiu que os participantes discutissem coletivamente o currículo de formação, metas e dificuldades em estabelecer uma proposta, em nível nacional, para formação de um professor de Ciências. Já naquele momento vislumbrava-se que, embora um núcleo básico fosse importante, a diversidade e as especificidades regionais deveriam ser diferenciadamente tratadas.

A síntese das apresentações indicou que todas são Licenciaturas plenas com foco prioritário no Ensino de Ciências no nível fundamental. Algumas apresentam habilitações em Ensino de Física, Química ou Biologia no nível médio; cursos mais antigos derivaram das denominadas "licenciaturas curtas" extintas e substituídas por cursos de LCN; em todas as apresentações houve a preocupação de estabelecer uma abordagem interdisciplinar ou integração das áreas, quando da elaboração dos currículos.

O evento permitiu aos docentes e pesquisadores em ensino de Ciências Naturais um momento de reflexão único, de troca de experiências e da necessidade de um debate maior sobre a criação de diretrizes curriculares específicas para Ciências Naturais. Ao longo de 2009, uma rede de debates se estabeleceu pela internet, que acabou envolvendo os alunos dos cursos em todo o país ${ }^{2}$.

2 Por meio de um grupo na rede de computadores o endereço LICENBrasil@yahoogrupos.com.br e http://groups.yahoo.com/group/LICENBrasil foi a base virtual a partir da qual se manteve a discussão iniciada em 2008, em Brasília.
Em 2010 a realização do $2^{\circ}$ Seminário Brasileiro de Integração das Licenciaturas em Ciências Naturais incorporou, além da reunião dos coordenadores/professores dos cursos, também a participação dos alunos, que demonstraram interesse em discutir a construção de diretrizes curriculares, perfil profissional, entre outros temas ${ }^{3}$.

Neste segundo encontro, um fato até então ainda não identificado pelo grupo inicial de 2008 ficou evidente: o aumento no número de cursos em todo o território brasileiro ${ }^{4}$, e, conjuntamente, realizou-se o $1^{\circ}$ Encontro Nacional de Estudantes de Ciências Naturais - ENECINA. A iniciativa foi extremamente propícia e a participação dos alunos no evento oportunizou a realização de oficinas, minicursos, palestras, conferências, assim como o diálogo dos discentes e docentes nos debates dentro dos grupos de discussão. ${ }^{5}$

Segundo Reis et al. (2020), com dados extraídos do Ministério da Educação (MEC) por meio do sistema e-MEC, em 2017 existiam 692 cursos de Licenciatura em Ciências Biológicas, 48 cursos denominados Licenciatura em Ciências Naturais e 14 cursos denominados Licenciatura em Ciências da Natureza. Essas licenciaturas eram ofertadas por 18 instituições públicas estaduais e federais (universidade, institutos federais e polos de educação à distância), distribuídas predominantemente nas regiões Nordeste e Norte. Ainda segundo os autores, na Região Sudeste tem ocorrido um decréscimo na oferta de LCN, a despeito do número de instituições públicas e privadas, algumas das quais mais renomadas nacional e internacionalmente.

Da mesma forma como se procedera em 2008, foram formados grupos de trabalho com as mesmas propostas iniciais, e aos alunos foi lançado o convite de

3 Realizado entre 13-15 de outubro de 2010, na Escola de Artes, Ciências e Humanidades (EACH), da Universidade de São Paulo (USP).

40 Centro Acadêmico do Curso de Licenciatura em Ciências da Natureza "Mário Schöenberg" da EACH-USP, realizou levantamento do número de cursos em todo o Brasil e conjuntamente realizou-se o $1^{\circ}$ Encontro Nacional de Estudantes de Ciências Naturais (Enecina).

5 Estiveram presentes os cursos da UFPA, UFAM, FUP-UnB, UFF e EACH-USP, que haviam participado do primeiro Seminário, e cursos novos ainda com turma de egressos não formadas, da Universidade Federal do Paraná (Litoral) (UFPR-Litoral), Universidade Federal do Pampa (Unipampa) campus Uruguaiana, Universidade Federal da Paraíba (UFPB), Universidade Federal do Vale do São Francisco (Univasf) campus Piauí, Bahia e Pernambuco. 
participação de grupos de interesse, cuja coordenação ficou a cargo de docentes das IES presentes, e relatoria dos próprios alunos. Após a conclusão dos trabalhos em grupo, os resultados foram sistematizados:

Grupo 1 - Diretrizes para o curso de Licenciatura em Ciências Naturais (LCN). Foram colocadas as seguintes questões: Quais seriam os grandes temas? Seriam aqueles propostos pelos PCNs? Para as questões de debate o grupo apresentou os seguintes pontos, a partir da discussão:

a. necessidade de se trabalhar as disciplinas pedagógicas desde o início do curso;

b. necessidade de uma base sólida nas áreas de Química, Física, Biologia e Geociências (Ciências da Terra, Ciências do Universo, Ciências da Vida, Física e Química);

c. o trabalho por meio de eixos temáticos pode propiciar interdisciplinaridade;

d. os PCN's seriam a referência para organização desses eixos temáticos.

Tabela 1. Cursos de LCN no Brasil e suas características

\begin{tabular}{|c|c|c|c|c|c|}
\hline IES & Título do Curso & Habilitação para Docência & $\begin{array}{l}\text { início } \\
\text { do } \\
\text { Curso }\end{array}$ & $\begin{array}{c}\text { Outras } \\
\text { Possibilidades }\end{array}$ & $\begin{array}{l}\text { Duração/ } \\
\text { Período }\end{array}$ \\
\hline $\begin{array}{l}\text { UFPR Litoral, } \\
\text { Campus Matinhos } \\
\text { Paraná }\end{array}$ & $\begin{array}{l}\text { Licenciatura em } \\
\quad \text { Ciências }\end{array}$ & $\begin{array}{l}\text { Ensino de Ciências no Ensino } \\
\text { Fundamental do } 6^{\circ} \text { ao } 9^{\circ} \text { ano }\end{array}$ & 2008 & $\begin{array}{c}\text { Divulgação } \\
\text { Científica, } \\
\text { Pesquisa ensino, } \\
\text { Produção } \\
\text { Material Didático } \\
\text { Regional }\end{array}$ & $\begin{array}{l}8 \text { semestres } \\
\text { Noturno }\end{array}$ \\
\hline $\begin{array}{l}\text { UFPA } \\
\text { Pará }\end{array}$ & $\begin{array}{c}\text { Licenciatura em } \\
\text { Ciências Naturais }\end{array}$ & $\begin{array}{l}\text { Ensino de Ciências no Ensino } \\
\text { Fundamental do } 6^{\circ} \text { ao } 9^{\circ} \text { ano }\end{array}$ & 2008 & & $\begin{array}{c}7 \text { semestres } \\
\text { Noturno }\end{array}$ \\
\hline $\begin{array}{c}\text { FUP, UnB, Campus } \\
\text { Planaltina } \\
\text { Brasília } \\
\end{array}$ & $\begin{array}{l}\text { Licenciatura em } \\
\text { Ciências Naturais }\end{array}$ & $\begin{array}{c}\text { Ensino de Ciências na Educação } \\
\text { Básica }\end{array}$ & 2006 & $\begin{array}{c}\text { Educador } \\
\text { Ambiental, } \\
\text { Pesquisa em } \\
\text { Ciências }\end{array}$ & $\begin{array}{c}9 \text { semestres } \\
\text { Noturno } \\
8 \text { semestres } \\
\text { Diurno }\end{array}$ \\
\hline $\begin{array}{l}\text { Unipampa, Campus } \\
\text { Uruguaiana, RS }\end{array}$ & \begin{tabular}{|c|} 
Licenciatura em \\
Ciências da Natureza \\
\end{tabular} & $\begin{array}{c}\text { Ensino Ciências EF; habilitações em } \\
\text { Física, Biologia e Química EM }\end{array}$ & 2010 & $\begin{array}{c}\text { Pesquisa na área } \\
\text { das Ciências }\end{array}$ & $\begin{array}{c}9 \text { semestres } \\
\text { Noturno }\end{array}$ \\
\hline $\begin{array}{l}\text { EACH-USP } \\
\text { São Paulo }\end{array}$ & $\begin{array}{c}\text { Licenciatura em } \\
\text { Ciências da Natureza } \\
\text { para o Ensino } \\
\text { Fundamental II }\end{array}$ & Ensino Fundamental II & 2005 & $\begin{array}{l}\text { Divulgação } \\
\text { Científica } \\
\text { em Museus, } \\
\text { Educador } \\
\text { Ambiental }\end{array}$ & $\begin{array}{l}8 \text { semestres } \\
\text { Diurno e } \\
\text { Noturno }\end{array}$ \\
\hline $\begin{array}{c}\text { Univasf } \\
\text { Senhor do Bonfim, } \\
\text { BA } \\
\text { São Raimundo } \\
\text { Nonato, PI } \\
\text { Bahia e Piauí } \\
\end{array}$ & $\begin{array}{c}\text { Licenciatura em } \\
\text { Ciências da Natureza }\end{array}$ & Ensino Fundamental I e II & 2009 & $\begin{array}{c}\text { Divulgação } \\
\text { Científica, } \\
\text { Pesquisa e Ensino }\end{array}$ & $\begin{array}{l}7 \text { semestres } \\
\text { Noturno }\end{array}$ \\
\hline $\begin{array}{l}\text { UFAM } \\
\text { Amazonas }\end{array}$ & $\begin{array}{l}\text { Licenciatura Plena em } \\
\text { Ciências Naturais }\end{array}$ & Ensino Fundamental & 1976 & $\begin{array}{c}\text { Divulgação } \\
\text { Científica, } \\
\text { Pesquisa Ensino } \\
\text { de Ciências }\end{array}$ & $\begin{array}{c}8 \text { semestres } \\
\text { Vespertino e } \\
10 \text { semestres } \\
\text { Noturno }\end{array}$ \\
\hline $\begin{array}{l}\text { UEPA, Belém + } 12 \\
\text { mun. do interior do } \\
\text { estado }\end{array}$ & $\begin{array}{l}\text { Licenciatura Plena em } \\
\text { Ciências Naturais }\end{array}$ & $\begin{array}{l}\text { Ciências EF, opção dentre três } \\
\text { habilitações: Física, Química e } \\
\text { Biologia }\end{array}$ & 2002 & $\begin{array}{l}\text { Atuação em } \\
\text { Museus }\end{array}$ & $\begin{array}{l}8 \text { semestres } \\
\text { Diurno }\end{array}$ \\
\hline $\begin{array}{l}\text { UFF, Santo Antônio } \\
\text { de Pádua, RJ }\end{array}$ & $\begin{array}{l}\text { Licenciatura em } \\
\text { Ciências Naturais }\end{array}$ & \multicolumn{2}{|c|}{ Primeira turma será formada em 2011} & & \\
\hline UFPB, Paraíba & $\begin{array}{l}\text { Licenciatura em } \\
\text { Ciências Naturais }\end{array}$ & \multicolumn{2}{|c|}{$\begin{array}{l}\text { Primeira turma formada em 2010; o curso } \\
\text { tem apenas } 2 \text { semanas de início das aulas }\end{array}$} & & \\
\hline \multicolumn{2}{|c|}{ (C) Terrae Didat. } & Campinas, SP & $1-9$ & $\mathrm{e} 020030$ & 2020 \\
\hline
\end{tabular}

Grupo 2 - Forma de avaliação dos cursos. O grupo discutiu as formas existentes de avaliação dos cursos pelo Ministério da Educação (MEC) e como resultados dos debates sugeriu um acréscimo aos itens já existentes neste sistema, tais como: entrevista com aluno por amostragem, realização de audiências públicas internas, das unidades que oferecem o curso com registro e a interação do curso com a comunidade e escolas, com projetos de extensão, pesquisa, apoio etc.

Grupo 3 - Perfil do futuro professor de Ciências Naturais. Esse grupo não foi formado, pois a plenária considerou que a apresentação prévia dos debates de 2008 foi um ponto que se julgou já bem definido, cabendo discutir de forma mais abrangente o item referente à atuação profissional.

Grupo 4 - Possibilidades de atuação do licenciando em Ciências Naturais. O grupo estabeleceu um levantamento de cada curso (Tab. 1), a partir do qual os próprios alunos apresentaram as possibilidades que cada região pode oferecer aos alunos egressos. 


\section{Licenciaturas em Ciências Naturais: cenários atual e futuro}

A universalização obrigatória da Educação Fundamental, se considerarmos somente a década de 2001-2010, demandaria cerca de 32 mil professores de Ciências para atender ao ensino do $6^{\circ}$ aos $9^{\circ}$ anos (Chaves \& Shellard, 2005, Razuck \& Rotta, 2014).

Em muitas universidades, tanto o perfil de formação em Ciências Biológicas dos docentes que, historicamente, atuam no ensino de Ciências Naturais do ensino fundamental, quanto os currículos de formação dos professores em Ciências Naturais, não atendem às atuais características da disciplina Ciências, estabelecidas pelas orientações curriculares, quer pelos Parâmetros Curriculares Nacionais (PCN), quer pela Base Nacional Comum Curricular (BNCC). Entendemos que a formação, em cursos desta natureza, não contempla plenamente as necessidades para atuação na disciplina ciências, em função da ausência de conhecimentos das outras áreas das Ciências Naturais, que não são abordadas nos cursos de Biologia, tais como Geociências, Astronomia etc.

Ressalta-se, ainda, que a BNCC, cujos objetivos no tocante ao ensino de Ciências da Natureza no Ensino Fundamental determinam o "acesso à diversidade de conhecimentos científicos"; "aproximação gradativa aos processos, práticas e procedimentos de investigação científica"; "fazer escolhas e intervenções conscientes pautadas nos princípios da sustentabilidade e do bem comum". Tais determinações envolvem princípios metodológicos, como contextualização, problematização, planejamento e implementação de ações investigativas, bem como intervenção na realidade (Neto, 2017) que, em geral estão ausentes na formação do professor.

Além disso, as exigências legais indicam que os professores devem ter formação específica em Ciências Naturais (Brasil, 2001), o que justifica a necessidade de implementação de cursos de LCN nas Universidades, com proposta de formação com uma visão ampla, integrada e interdisciplinar das áreas de Química, Biologia, Física e Geologia.

De acordo com a UNESCO, segundo o Conselho Internacional para a Ciência, durante a Conferência Mundial sobre a Ciência para o Século XXI, realizada em Budapeste no ano de 1999:

Para um país ter a capacidade de atender às necessidades básicas da sua população, a educação científica e tecnológica é uma necessidade estratégica. Como parte dessa educação, os alunos devem aprender a solucionar problemas específicos e a abordar as necessidades da sociedade, utilizando os seus conhecimentos e as suas habilidades científicas e tecnológicas (UNESCO, 2003).

De fato, os conhecimentos de natureza científica e tecnológica, cada vez mais valorizados na sociedade atual, têm como principal característica um permanente e rápido processo de transformação. $\mathrm{O}$ ensino de Ciências no Ensino Fundamental pressupõe a formação de um cidadão crítico e participativo, tais conhecimentos devem promover a ampliação de sua compreensão do mundo, preparando-o para ser agente de mudanças qualitativas. Nesse contexto, o ensino de Ciências Naturais, já nos documentos anteriores à BNCC, apontavam como um "espaço privilegiado em que as diferentes explicações sobre o mundo, os fenômenos da natureza e as transformações produzidas pelo homem podem ser expostos e comparados" (Brasil, PCN-Ciências, 1999, v. 4, p. 25).

Gil-Pérez et al. (1991) apontam que ao professor em formação ou em exercício, quando solicitado que expresse sua opinião sobre "o que nós, professores de Ciências, deveríamos conhecer em um sentido mais amplo de saber e saber fazer para podermos desempenhar nossa tarefa e abordar de forma satisfatória os problemas que esta nos propõe", as respostas são, em geral, bastante pobres e não incluem muitos dos conhecimentos que a pesquisa destaca como fundamentais.

As constantes transformações sociais, políticas e ambientais ocorridas na sociedade nas últimas décadas têm imposto ao ensino de ciências a necessidade de constantemente reformular seus pressupostos. Assim, quando confrontamos as configurações epistêmicas contemporâneas e as novas demandas sociais e políticas que se colocam para a escola em um contexto em transformação, devemos discutir o papel do Professor na sociedade moderna, e, na mesma medida, deve ser colocada a necessidade de formar um profissional capaz de enfrentar os desafios mais urgentes. Pierson \& Neves (2000) apontam preocupação com a natureza dos problemas gerados pelas transformações socioeconômicas que afligem a sociedade, trazendo à tona a discussão que tem como centro o modelo de produção do conhecimento baseado na racionalidade técnica, ao mesmo tempo em que colocam em questão a fragmentação causada pela excessiva especialização das ciências em suas disciplinas; divisão que remonta às diretrizes do paradigma positivista.

A divisão do conhecimento em áreas para um estudo aprofundado, imposta desde o século XIX, influenciou o desenvolvimento das ciências, espe- 
cialmente das Ciências Naturais. Observa-se que problemas complexos gerados pelo desenvolvimento das sociedades, difíceis de ser resolvidos por especialistas de forma isolada - como a questão do desenvolvimento autossustentável, por exemplo, carecem de visão sistêmica e interdisciplinar, que não se caracteriza na Educação Científica realizada nas escolas. Assim, em oposição ao modelo fragmentário de produção de conhecimentos e de ensino, emerge o paradigma da interdisciplinaridade, que deveria pautar a formação do professor em cursos de LCN, em virtude do caráter integrador da disciplina de Ciências da Natureza no ensino fundamental, que estrutura e organiza seu currículo ao redor de conhecimentos de diferentes áreas disciplinares (Química, Física, Biologia, Astronomia e Geologia).

Assim, os trabalhos efetivados durante o $2^{\circ}$ Seminário Brasileiro de Integração das Licenciaturas em Ciências Naturais propôs a criação do Fórum Nacional de Cursos de LCN, tendo como objetivo organizar regionalmente as IES que mantêm tais cursos de forma que os aspectos levantados pelos grupos de trabalho possam ser desenvolvidos, tendo como prioridades realizar os seguintes levantamentos:

a. Histórico: levantar o histórico dos cursos de LCN seja a partir da transição das "licenciaturas curtas", ou de uma demanda específica de professores para atuarem no ensino fundamental. Estabelecer esta pesquisa por região, visando identificar necessidades e especificidades próprias;

b. Secretarias Estaduais e Municipais de Educação (SEDUC): Inserção dos egressos nas SEDUC; realizar levantamento de como ocorre à inserção desse egresso, que normas, legislações, portarias são utilizadas, se atendem às necessidades dos alunos formados, como se dá o processo de acesso em concursos, possibilidades e atuação no ensino médio (legislação);

c. Levantamento dos cursos de LCN no Brasil e seus respectivos PPP; a partir desse encontro, identificar outros cursos existentes em todas as modalidades (graduação formal, ensino a distância (EAD), formação continuada, etc.) e em todo o território nacional; levantar os PPP existentes;

d. Levantamento dos itens currículo e grade, tanto no que se refere aos conteúdos básicos quanto às especificidades regionais. O levantamento indicar-nos-á quais elementos deverão compor uma diretriz curricular nacional para a formação do licenciado em Ciências Naturais.

Os resultados atingidos nos encontros mostraram que os cursos de LCN tem se ampliado em todo o País, porém não existia diálogo entre aqueles que trabalham em sua construção, principalmente no que concerne aos currículos formativos. A falta de um espaço para debates, encontros, trocas de experiências mostrou a urgência de um diálogo, como a criação do Fórum que possibilitaria a alunos, professores e coordenadores discutirem problemas comuns, tais como a atuação profissional, além daquela prevista para a docência, em áreas nas quais inexistem profissionais com habilidades e competências, Além disso, é preciso garantir ao egresso o caráter de educador ambiental, pela formação holística e a visão sistêmica que as Ciências Naturais permitem a esse profissional, e em várias outras atividades, tais como espaços não formais de ensino de ciências (museus, feiras, parques temáticos, exposições temáticas etc.), no âmbito do jornalismo científico e outras.

Desta forma, ao divulgar os resultados obtidos durante o $2^{\circ}$ Seminário Brasileiro de Integração das Licenciaturas em Ciências Naturais, estabelecemos um trabalho inédito no Brasil, para o qual ainda não se identificavam dados básicos por região, para além da possibilidade de organização dos alunos em cursos de LCN em todo o território nacional no ENECINA.

Efetivamente, os cursos de LCN no país se multiplicaram, tendo havido uma migração: os cursos eram inicialmente oferecidos somente em universidades públicas, mas nos últimos anos encontramos propostas de cursos em instituições privadas, além de diversos cursos na modalidade não presencial (Ensino a Distância, EAD), em diferentes localidades. Outro fator importante é a oferta, em diferentes universidades, de cursos de LCN que habilitam, também, em Física, Química e Biologia. Tal iniciativa vem de encontro à falta de professores dessas disciplinas para o ensino médio.

Em análise recente Reis \& Mortimer (2020) evidenciaram de que forma as disciplinas pedagógicas, pedagógicas de conteúdo e metacientíficas acabaram valorizando os cursos de LCN por eles analisados.

Isso indica um movimento nas licenciaturas em Ciências da Natureza na direção de uma formação acadêmico-profissional que seja capaz de introduzir o professor em uma nova forma de pensar o ensino e a aprendizagem que rompa com visões reducionistas: de um ensino prioritariamente biologizado; de que ensinar é fácil; da existência de um método científico único e verdadeiro; de que 
o ensino fundamental, nos anos finais, é apenas um período de transição para o ensino médio; e tantas outras visões que permeiam essa etapa da escolarização (Reis \& Mortimer, 2020).

\section{Considerações Finais}

Além de identificar a grande expansão dos cursos de Licenciatura em Ciências Naturais no território nacional, um resultado relevante dos Seminários realizados foi o estabelecimento do Enecina, como atividade integradora dos estudantes, que está na oitava edição, a ser realizada pelos alunos da EACH-USP, em 2020. Outro fator importante foi a organização do Congresso Nacional de Ciências Naturais, por parte dos alunos, em sua quarta edição, que ilustra elevada produção científica acadêmica e acentua a importância dos cursos na formação de professores para a educação básica, não somente na área de Ciências da Natureza, mas em diversas outras áreas que carecem de professores, principalmente no ensino médio.

\section{Referências}

Brasil. Ministério da Educação e do Desporto. Secretaria da Educação Fundamental. (1998). Parâmetros Curriculares Nacionais: Ciências Naturais. Brasília: $\mathrm{MEC} / \mathrm{SEF}$.

Brasil. Secretaria de Educação Fundamental. (1999). Referenciais para formação de professores. Brasília: MEC/SEF.

Conselho Nacional de Educação (CNE). (2019). Diretrizes Curriculares Nacionais para a Formação Inicial de Professores para a Educação Básica. Base Nacional Comum para a Formação Inicial de Professores da Educação Básica (BNC-Formação). Resolução CNE/CP n ${ }^{\circ} 2$, de 20 de dezembro de 2019. Brasília-DF: CNE. http://portal. mec.gov.br/index.php?option $=$ com_docman\&view $=$ download $\&$ alias $=135951-\mathrm{rcp} 002-19 \&$ cate gory_slug=dezembro-2019-pdf\&Itemid $=30192$. Acesso 08.06.2020.

Chaves, A., \& Shellard, R. C. (2005). Física para o Brasil: pensando o futuro. São Paulo: Sociedade Brasileira de Física, 2005. URL: http://www.sbfisica.org.br/v1/ arquivos_diversos/publicacoes/FisicaBrasil_Dez05. pdf. Acesso 23.03.2019.

Compiani, M. (2005). Geologia/Geociências no Ensino Fundamental e a Formação de Professores. Revista IG-USP, 3, 13-30.

Gil-Pérez, D., Carrascosa, J., Furió, C., \& MartínezTorregrosa, J (1991) La enseñanza de las ciencias en la educación secundaria. Barcelona, Horsori.

Instituto Nacional de Estudos e Pesquisas Educacionais Anísio Teixeira (INEP). (2019). Relatório Brasil no PISA 2018. Versão Preliminar. Coords. Nascimento, C. D'L. \& Borges, V. M. Brasília-DF: Inep/ MEC. 160p. URL: http://download.inep.gov.br/ acoes_internacionais/pisa/documentos/2019/relato-
rio_PISA_2018_preliminar.pdf. Acesso 15.05.2020.

Krasilchik, M. (1980). Inovação no ensino de ciências. In: Garcia, Walter. (Coord.) (1980). Inovação educacional no Brasil: problemas e perspectivas. São Paulo: Cortez Autores Associados.

Krasilchik, M. (1987) O professor e o currículo das ciências. São Paulo: EPU/EDUSP.

Nardi, R. (2005) Memórias da educação em ciências no Brasil: a pesquisa em ensino de física. Investigações em Ensino de Ciências, 10(1), 63-101.

Neto, J. M. (2014). Parecer analítico sobre a BNCC-Ciências da Natureza. URL: http://basenacionalcomum.mec.gov.br/images/relatorios-analiticos/ Parecer_8_CI_Jorge_Megid_Neto.pdf. Acesso 09.06.2020.

Oliveira, J. F.; Imbernon, R. A. L. (2014). Avaliação dos Projetos Políticos Pedagógicos (PPP) de cursos de Licenciatura em Ciências Naturais (LCN) no Brasil. Conferência In: $3^{\circ}$ Seminário Brasileiro de Integração das Licenciaturas em Ciências Naturais. Faculdade UnB Planaltina (FUP), Universidade de Brasília (UnB).

Pierson, A. H. C., \& Neves, M. R. (2000). Interdisciplinaridade na formação de professores de ciências: conhecendo obstáculos. Porto Alegre, Revista Brasileira de Pesquisa em Educação em Ciências, 1(2), 120-131.

Pontuschka, N. N. A. (1994). A formação pedagógica do professor de geografia e as práticas interdisciplinares. Tese (Doutorado em Educação). São Paulo, Faculdade de Educação, Universidade de São Paulo.

Razuck, R. C. S. R., \& Rotta, J. C. G. (2014). O curso de licenciatura em Ciências Naturais e a organização de seus estágios supervisionados. Ciênc. Educ., Bauru, 20(3), 739-750. doi: 10.1590/151673132014000300014.

Reis, R. C., \& Mortimer, E. F. (2020). Um estudo sobre Licenciaturas em Ciências da Natureza no Brasil. EDUR Educação em Revista, 36, 1-13. doi: 10.1590/0102-4698205692.

Ristoff, D. (2012). A tríplice crise na formação de professores. GEA-ES, FLACSO-Brasil, Fundação Ford.

Saviani, D. (2006) A nova lei da educação: LDB trajetória, limites e perspectivas. Campinas: Autores Associados.

Soares, S. S. D., \& Nascimento, P. A. M. M. (2012) Evolução do desempenho cognitivo dos jovens brasileiros no Pisa. Cadernos de Pesquisa 42(145), 68-87. doi: 10.1590/S0100-15742012000100006.

Souza, R. T. Y. B., Souza, L. O., Oliveira, S. R., \& Takahashi, E. L. H.(2019) Formação continuada de professores de ciências utilizando a Aquaponia como ferramenta didática. Ciência \& Educação 25(2), 395-410. doi: 10.1590/1516-731320190020008.

Villani, A., Pacca, J. L. A., \& Freitas, D. (2002). Formação do Professor de Ciências no Brasil: Tarefa Impossivel? Atas do VIII Encontro Nacional de Pesquisa em Ensino de Física. São Paulo: Sociedade Brasileira de Física. v. único. p. 1-20.

UNESCO (2003). A ciência para o século XXI: uma nova visão e uma base de ação. Brasília: UNESCO, ABIPTI, 2003. 72p. Texto baseado na Conferência Mundial sobre Ciência, Santo Domingo, 10-12 mar, 1999 e na Declaração sobre Ciências e a Utilização do Conhecimento Científico, Budapeste, 1999. http://www.dominiopublico.gov.br/download/texto/ue000207.pdf. Acesso 09.06.2020.

\begin{tabular}{c|c|c|c|c|c}
\hline (C) Terrae Didat. & Campinas, SP & v.16 & $1-9$ & $\mathrm{e} 020030$ & 2020 \\
\hline
\end{tabular}

